\begin{tabular}{l} 
DURNAI, R IS'I \\
(Rekayasa Sistem dan Teknologi Informasi) \\
Vol. 3 No. 2(2019) $227-232 \quad$ ISSN Media Elektronik: 2580-0760 \\
\hline
\end{tabular}

\title{
Klasifikasi Berita Menggunakan Algoritma Naive Bayes Classifer Dengan Seleksi Fitur Dan Boosting
}

\author{
Bobby Suryo Prakoso ${ }^{1}$, Didi Rosiyadi ${ }^{2}$,Heru Sukma Utama ${ }^{3}$,Dedi Aridarma ${ }^{4}$ \\ ${ }^{1}$ Magister Ilmu Komputer, Fakultas Ilmu Komputer, STMIK Nusa Mandiri Kramat \\ ${ }^{2}$ Fakultas Ilmu Komputer, STMIK Nusa Mandiri Kramat \\ ${ }^{2}$ Fakultas Teknik Informasi, Universitas Bina Sarana Informatika \\ ${ }^{2}$ Pusat Penelitian Informatika LIPI \\ ${ }^{3,4}$ Magister Ilmu Komputer, Fakultas Ilmu Komputer, STMIK Nusa Mandiri Kramat \\ ${ }^{1} 14002107 @$ nusamandiri.ac.id
}

\begin{abstract}
This research is part of text mining for the classification of news content that already has labels based on the category of news on the site detik.com. The process carried out is to do data modeling and processing, start the pre-processing process, information gain feature selection process, and the application of the Naive Bayes Classifier algorithm model with Bayesian Boosting. The results obtained from the model get an evaluation value of accuracy, recall, and precision of $73.2 \%$. Whereas the more concise model is the Naive Bayes Classifier algorithm model, with Bayesian Boosting getting the same evaluation value of $73.2 \%$. The evaluation of the results of the evaluation model that has been implemented concludes that the application of the Information Gain feature does not have a large effect on the increase in performance results on the condition of the Polynomial label..
\end{abstract}

Keywords: Information Gain, Naive Bayes Classifier, Boosting, Bayesian Boosting

\begin{abstract}
Abstrak
Penelitian yang dilakukan ini merupakan bagian dari text mining untuk klasifikasi konten berita yang telah memiliki label berdasarkan katagori berita pada situs detik.com . Proses yang dilakukan adalah melakukan permodelan dan pengolahan data, mulai proses pre-processing, proses seleksi fitur information gain, dan penerapan model algoritma Naive Bayes Classifier dengan Bayesian Boosting. Hasil yang diperoleh atas model tersebut mendapatkan nilai evaluasi terhadap akurasi, recall, dan presisi sebesar $73.2 \%$. Sedangkan dengan model yang lebih ringkas yaitu model algoritma Naive Bayes Classifier, dengan Bayesian Boosting mendapatkan nilai evaluasi yang sama besar yaitu $73.2 \%$. Penilaian atas hasil evaluasi model yang telah terlaksankan berkesimpulan bahwa penerapan seleksi fitur Information Gain tidak berpengaruh besar atas kenaikan hasil performa terhadap kondisi label Polynomial.
\end{abstract}

Kata kunci: Information Gain, Naive Bayes Classifier, Boosting, Bayesian Boosting

(C) 2019 Jurnal RESTI

\section{Pendahuluan}

Klasifikasi teks banyak mengenalnya sebagai bagian mendefinisikan satu atau lebih katagori untuk dokumen berbahasa natural. Jika pada dasarnya klasifikasi dokumen secara manual atau dengan aturan klasifikasi otomatis yang terumuskan oleh manusia, banyak Pemanfaatan internet saat ini yang menarik adalah algoritma machine learning digunakan untuk untuk bidang sosial - politik dengan presentase mengklasifikasikan teks ataupun berita secara otomatis penggunaan sebagai berikut berita sosial lingkungan yang tidak terlihat berdasarkan data training atau data sebesar 50,26 \%, berita informasi agama $41,55 \%$, berita testing yang telah diberi label oleh manusia.
Mengingat semakin banyaknya file dokumen online yang tersedia melalui internet diantaranya berita online, email dan perpustakaan digital, tugas ini sangat penting secara praktis dapat mengklasifikasikan lebih terstruktur.

politik $39,94 \%$ dan kegiatan amal sebesar $16,31 \%$.

Diterima Redaksi : 22-07-2019 | Selesai Revisi : 29-07-2019| Diterbitkan Online : 03-08-2019 
Berdasarkan data teserbut bahwa pemberitaan online pun menjadi media yang digunakan untuk memperoleh informasi tersebut[1].

Penelitian yang dilakukan oleh Shuo $\mathrm{Xu}$, yang mengklasifikasikan berita menggunakan algoritma Naive Bayes Classifier dengan menggabungkan metode Gausian Event Model dan Multinomial Event Model. Terhadap 20 katagori berita yang digunakan, dengan masul untuk gausian Gausian Event Model memiliki hasil yang lebih baik setelah diperbandingkan, dengan hasil akurasi $88 \%$ [2].

Selanjutnya tentang analisis sentimen dengan Berikut untuk contoh untuk formula dalam menggunakan algoritma Naive Bayes Classifier dan pengambilan data diantaranya ada untuk pengambilan ditambahkan fitur seleksi Chi Square untuk URL : menentukan rekomendasi atas lokasi restoran dengan tema tradisional. Berdasarkan perhitungan yang dilakukan untuk penelitian tersebut terdapat beberapa skenario pengujuan yang diantaranya untuk nilai $C h i$ Square 25\% mendapatkan akurasi $81 \%$, Chi Square $50 \%$ mendapatkan $80 \%$, Chi Square $75 \%$ mendapatkan akurasi $77 \%$, dan yang terkahir Chi Square 100\% mendapatkan akurasi $80 \%$. Dengan kesimpulan untuk penggunaan Chi Square tidak terlalu berpengaruh[3].

Kemudian tentang penelitian yang dilakukan oleh Dio Ariadi dan Kartika Fithriasari, yang melakukan klasifikasi berita dengan menggunakan metode Naive Bayes Classifier dengan menambahkan confix stripping stemmer. Detail tentang penelitian ialah mengunakan 12 katagori berita dengan menggunakan 100 berita setiap masing masing katagori. Hasil akhir atas penelitian tersebut untuk algoritma Naive Bayes Classifier performa akurasi, presisi, dan recall sebesar $82,2 \% 83,9 \%$ dan 82,2\%. Sedangkan untuk algoritma Support Vector Machine akurasi, presisi, dan recall adalah $88,1 \%, 89,1 \%$, dan $88,1 \%$ [4].

Berikutnya masih membahas untuk klasifikasi teks yang berbasis analisa sentimen terhadap pariwisata pada kota malang, dengan data yang diambil dari situs tripadvisor.com pada bagian komentar yang diberikan pada tempat wisata. Metode yang digunakan adalah algoritma Naive Bayes Classifier dengan seleksi fitur Query Expansion Ranking untuk mengurangi jumlah fitur pada proses klasifikasi, yang mendapatkan hasil akurasi sebesar 86.6\%.[5]

Berdasarkan rujukan penelitian yang ada, tentang kombinasi penggunaan seleksi pembobotan seleksi fitur dan boosting untuk model perhitungan dalam klasifikasi pengolahan teks. Baik dari penggunaan

Atas dasar landasan yang diberikan maka mucul Stemming adalah proses untuk mengurangi kata-kata beberapa pertanyaan, diantaranya adalah bagaimana yang berimbuhan menjadi bentuk dasarnya, dan hasil mendapatkan data, proses pre-processing data, seleksi dari stemming ini merupakan hal yang akan menjadi

fitur yang akan digunakan, dan terakhir metode dasar akan dirubahnya dari teks menjadi nominal[8]. algoritma yang digunakan. Hal inilah yang menjadi tujuan dari penelitian ini.
Formula Google spreadsheet

(Pengambilan URL)

=IMPORTXML ("https://news.detik.com/berita/dderi-bersembunyi", "//a/@href")

Formula tersebut sudah tersedia pada menu help yang telah disediakan pada google spreadsheet.

\subsection{Teks Pre-Processing}

Dalam hal teks pre-processing merupakan suatu cara atau proses didalam sebelumnya adalah bentuk tidak teks menjadi nominal term index). Tujuannya adalah untuk memperkecil dimensi data sehingga proses komputasi lebih menjadi efisien dan diharapkan lebih presisi.

Preprocessing terdiri dari beberapa tahapan. Adapun tahapan preprocessing berdasarkan, yaitu : case folding, tokenizing/ parsing, filtering dan stemming [7].

Dalam proses pertama ada case folding, yang merupakan suatu proses merubah teks menjadi seragam, bisa dalam bentuk huruf kecil semua, atau menjadi huruf besar semua. Selanjutnya adalah proses tokenizing, yaitu proses isi teks menjadi beberapa satuan kata.

Filtering merupakan tahap proses setelah proses tokenizing, yaitu proses membuang kata-kata tidak memiliki makna, seperti contohnya adalah "yang", "apa", "dengan", dan lain sebagainya. Selanjutnya dalam proses filtering terdapat menyimpan kata yang dianggap penting atau bisa masuk dalam data yang digunakan sebagai perhitungan. 4547868/jadi-aktor-mutilasi-di-mana-pradaterstruktur menjadi terstruktur, seperti contoh (merubah 


\subsection{Seleksi Fitur Information Gain}

Seleksi Fitur Information Gain merupakan suatu teknik Pada pembahasan kali ini untuk proses penelitian akan dalam mengurangi jumlah fitur yang sesuai atau dilakukan secara bertahap, mulai dari proses relevan, lalu mengurangi dimensi fitur pada data yang pengambilan data, tahap pre-processing, tahap seleksi akan digunakan. Untuk menghitung infomation gain fitur, dan tahap proses validasi. Dengan menggunakan menggunakan hitungan sebagai berikut[9] :

$\operatorname{info}(D)=-\sum_{i=1}^{c} p_{i} \log _{2}\left(p_{i}\right)$

(1)

Keterangan dari rumus tersebut adalah:

$$
\begin{array}{ll}
c & \begin{array}{l}
\text { : jumlah nilai yang ada pada atribut target } \\
\text { (jumlah kelas klasifikasi) }
\end{array} \\
p_{i} & \text { : jumlah sampe untuk kelas } i \\
\text { info }_{A}(D)=-\sum_{j=1}^{v} \frac{\left|D_{j}\right|}{|D|} x \text { info }\left(D_{j}\right)
\end{array}
$$
data berita dari situs berita online yang digunakan untuk pengambilan data. Tahapan proses yang dilakukan :

\subsection{Pengambilan Dataset}

Proses pengambilan data menggunakan tools yang telah disediakan oleh google, dengan google spreadsheet. Serta sumber data mengambil dari situs detik.com. Berikut merupakan proses ekstraksi link yang akan (2) menjadi dataset untuk digunakan:

Keterangan dari rumus tersebut adalah:

$$
\begin{array}{ll}
A & : \text { atribut } \\
|D| & : \text { jumlah seluruh sampel data } \\
\left|D_{j}\right| & : \text { jumlah sampel untuk nilai j } \\
v & : \text { suatu nilai yang mungkin untuk atribut } A
\end{array}
$$

Selanjutnya nilai information gain yang akan dipakai Dalam hal ini untuk labeling berdasrkan link dari hasil dengan dihitung menggunakan rumus dibawah ini[10] : ekstraksi yang sebelumnya dilakukan pencarian pada

$\operatorname{Gain}(A)=\left|\operatorname{info}(D)-\operatorname{info} o_{A}(D)\right|$

(3)

\subsection{Algoritma Naive Bayes Classifier}

Naive Bayes adalah metode algoritma yang bekerja atas bagaimana menghitung frekuensi atas setiap term yang ada dalam dokumen [5]. Dokumen dengan urutan kejadian yang muncul atas kata terhadap dokumen akan diabaikan, menyebabkan pengolahan kata menggunakan distiribusi yang multinomial[11].

Berikut persamaan rumus atas Naive Bayes Classifier [12]:

$$
\begin{array}{ll}
P(c \mid d)= & P(c) \prod_{i=1}^{n} P\left(w_{i} \mid c\right) \\
d & : \text { besaran dokumen } \\
n & : \text { jumlah semua kata yang ada pada dokumen }
\end{array}
$$

Selanjutnya nilai atas variabel $P(c)$ diperoleh dengan rumus berikut

$$
P(c)=\frac{N_{c}}{N}
$$

$$
\begin{array}{ll}
P(c) & : \text { peluang kelas } c \\
N & : \text { jumlah seluruh dokumen }
\end{array}
$$

Selanjutnya untuk menghitung peluang kata ke- $i$ pada kelas $c$ menggunakan rumus berikut :

$$
\begin{array}{ll}
P\left(w_{i} \mid c\right)=\frac{\operatorname{count}\left(w_{i}, c\right)+1}{\operatorname{count}(c)+|V|} \\
P\left(w_{i} \mid c\right) & : \text { Peluang kata ke- } i \text { pada kelas } c \\
\text { count }\left(w_{i}, c\right) & \text { : Jumlah kata ke- } i \text { pada kelas } c \\
\text { count }(c) & \text { : Jumlah semua kata pada kelas } c \\
|V| & \text { : Jumlah kata unik terhadap semua } \\
& \text { Kelas }
\end{array}
$$

(4) Setelah data terkumpul maka, seluruh data dikumpulkan pada suatu file untuk menjadi kesatuan dengan contoh format berikut, Taabel 1.

situs detik.com, dengan kata kunci pencarian Pendidikan, Politik, dan Budaya. Selanjutnya adalah ekstraksi proses isi berita dengan menggunakan formula berikut :

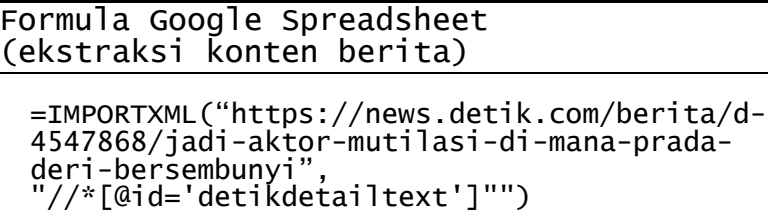

Tabel 1.Contoh Susunan Dataset Terkumpul

\begin{tabular}{ll}
\hline TEMA_BERITA & KONTEN_BERITA \\
\hline PENDIDIKAN & Jakarta - Pernah terbayang ada ....... \\
PENDIDIKAN & Jakarta - Tujuh hari jelang ......... \\
POLITIK & Jakarta - menyebut pertemuan ...... \\
POLITIK & Jakarta - Setan Gundul yang di..... \\
LINGKUNGAN & Jakarta-Terhadap penelitian sehingga.. \\
LINGKUNGAN & Jakarta- Pengajaran lingkungan .... \\
\hline
\end{tabular}

\subsection{Proses Pre-Processing}

(6) Setelah dataset terkumpul, maka selanjutnya adalah proses untuk memulai pengolahan data, yaitu proses pre-processing. Tahapan pertama adalah proses menghilangkan link yang masih ada pada dataset pada konten berita tersebut diantaranya dengan menggunakan operator yang telah tersedia pada tools Rapidminer, yaitu dengan operator Replace dengan 
menggunakan Regex, berikut untuk regex yang terpakai dan gambar operator yang terpakai pada Rapidminer beserta:

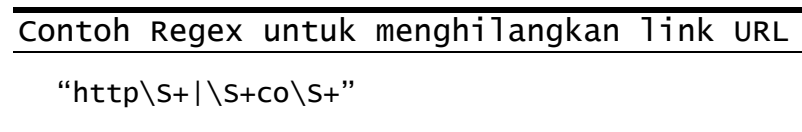

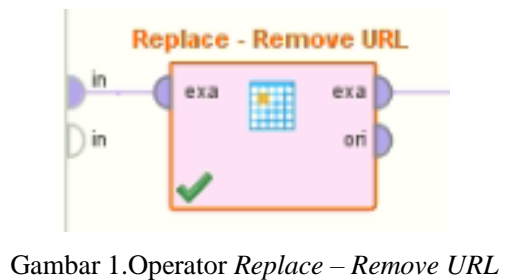

Atas proses operator tersebut maka akan menghasilkan contoh pada tabel 2 berikut ini :

Tabel 2.Contoh Replace URL

\begin{tabular}{lll}
\hline No & Konten Awal & Konten Akhir \\
\hline 1 & Dengan siapa dia.com & Dengan siapa \\
2 & $\begin{array}{l}\text { Siapa sih } \\
\text { temannya.com }\end{array}$ & Siapa sih \\
3 & $\begin{array}{l}\text { Aku telah melihat situs } \\
\text { https:IImenang.com }\end{array}$ & $\begin{array}{l}\text { Aku melihat situs } \\
\text { melah }\end{array}$ \\
\hline
\end{tabular}

Setelah melalui proses tersebut maka berlanjut pada proses berikut ini :

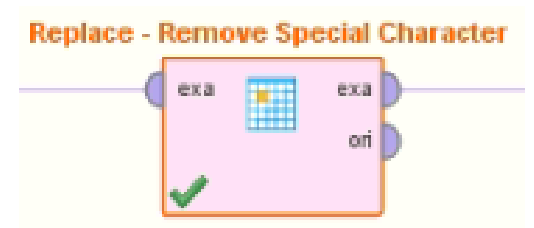

Gambar 2.Operator Replace - Remove Special Character

Yang menghasilkan contoh proses sebagai berikut, Tabel 3.

Tabel 3.Contoh Replace - Remove Special Character

\begin{tabular}{lll}
\hline No & Konten Awal & Konten Akhir \\
\hline 1 & Dengan siapa ?!!!! & Dengan siapa \\
2 & Siapa sih ^\&*(@(\#*!^ & Siapa sih \\
3 & Aku telah melihat situs & Aku telah \\
& )$\left.\left.^{*}\right) @ * \#\right) !$ & melihat situs \\
\hline
\end{tabular}

Proses selanjutnya adalah menentukan label yang digunakan dan merubah nilai yang nominal menjadi dalam bentuk text sebelum masuk proses selanjutnya :

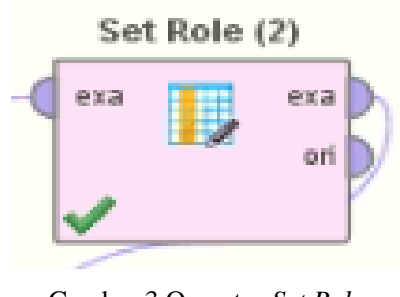

Gambar 3.Operator Set Role

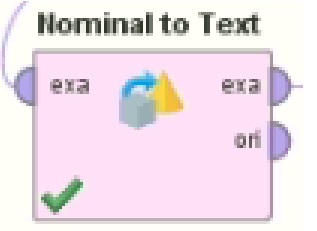

Gambar 4.Operator Nominal to Text

Jika data sudah sesuai maka data akan diteruskan kepada operator Process Documents from Data :

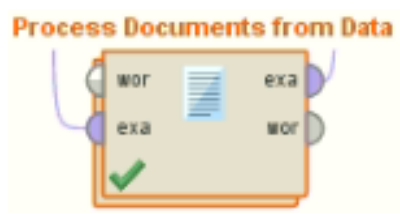

Gambar 5.Operator Process Documents from Data

Operator tersebut terdapat proses tahapan diantaranya mulai dari Tokenize, Transform Case, Filter Tokens, Filter Stopwords, dan Stemming. Berikut untuk gambar detail operatornya :

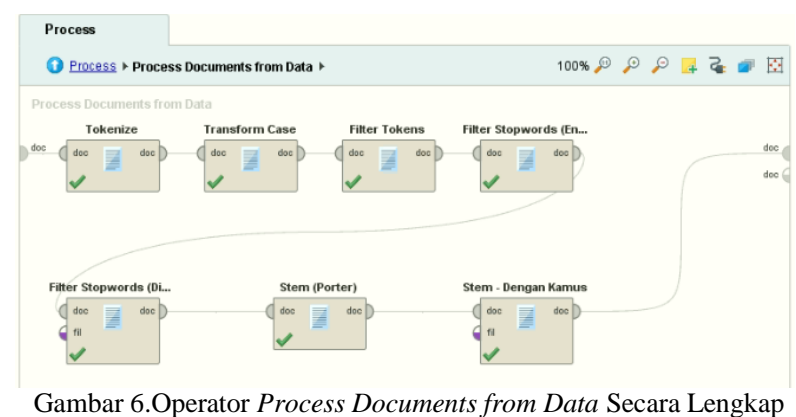

\subsection{Proses Seleksi Fitur Information Gain}

Setelah proses pre-processing atas dataset yang ada, maka selanjutnya diteruskan kepada proses menghilangkan attribut yang yang tidak terpakai diantaranya yaitu menggunakan operator Remove Useless Attributes, berikut operator yang tersedia:

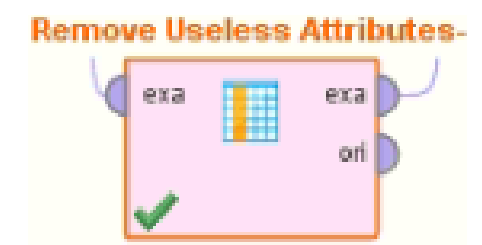

Gambar 7.Operator Remove Useless Attributes

Proses selanjutnya adalah pembobotan dengan menggunakan operator Information Gain dengan menggunakan operator yang telah tersedia pada Rapidminer, berikut untuk gambar operator yang digunakan : 


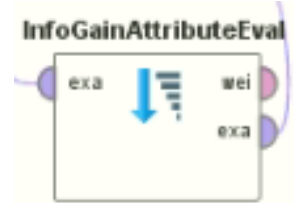

Gambar 8. Operator Information Gain

\subsection{Proses Validasi Algoritma}

Pada proses ini menggunakan beberapa operator, sebelumnya menggunakan operator cross validation dengan k-10 fold cross validation. Berikut untuk operator yang digunakan :

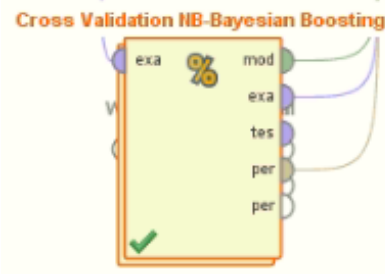

Gambar 9. Operator Cross Validation K-Fold

Yang didalamnya terdapat berbagai operasi diantaranya sebagai berikut :

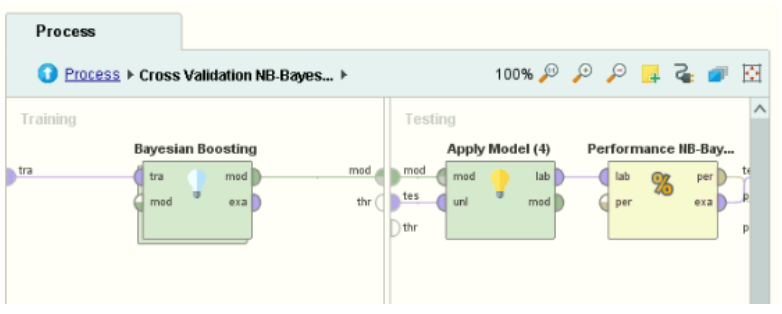

Gambar 10. Kumpulan Operator Cross Validation

Dengan proses pertama yaitu proses bayesian boosting untuk memaksimalkan hasil dari perhitungan algoritma Naive Bayes Classifier, berikut untuk gambar operatornya :

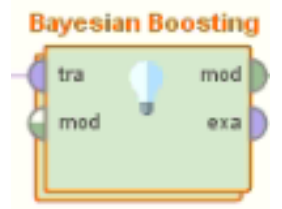

Gambar 11. Operator Bayesian Boosting

Pada Bayesian Boosting, proses sederhana yang dapat dijelaskan adalah melakukan boost untuk pengulangan atau iterasi atas penggunaan algoritma Naive Bayes Classifier untuk mendapat hasil yang lebih baik. Dengam melakukan iterasi default 10, tetapi pada penelitian ini menggunakan iterasi 30.

Pada Bayesian Boosting didalamnya terdapat Naive Bayes Classifier, berikut untuk contoh operatornya :

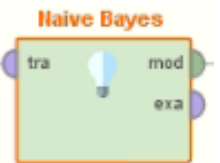

Gambar 12. Operator Naive Bayes

Setelah itu dilakukan penerapan model dengan operator Apply Model berikut ini :

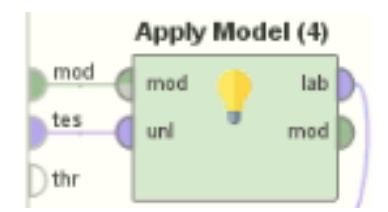

Gambar 11. Operator Apply Model

Setelah itu menghitung performa yang muncul terhadap penerapan model dengan metode $k-10$ fold, yaitu dengan memecah $10 \times 10$ dataset yang dijadikan data training dan terhadap 1 bagian yang akan digunakan menjadi data testing.

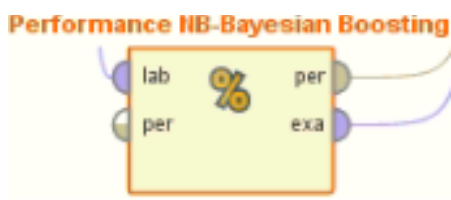

Gambar 11. Operator Performance-NB-Bayesian Boosting

\subsection{Hasil Penelitian}

Atas percobaan tersebut, penelitian ini membuat beberapa skenario yang digunakan dengan 4 model, berikut hasil yang didapat, Tabel 3.

Tabel 3. Hasil Cross Validation $K-10$

\begin{tabular}{llll}
\hline Model & Akurasi & Presisi & Recall \\
\hline NBC & $72 \%$ & $72.3 \%$ & $72.3 \%$ \\
IG-NBC & $69.5 \%$ & $69.6 \%$ & $69.6 \%$ \\
Bayesian Boosting-NBC & $73.2 \%$ & $73.2 \%$ & $73.2 \%$ \\
IG-Bayesian Boosting-NBC & $73.2 \%$ & $73.2 \%$ & $73.2 \%$ \\
\hline
\end{tabular}

\section{Kesimpulan}

Hasil penelitian menunjukan bahwa penerapan seleksi fitur information gain tidak memiliki pengaruh pada label yang bersifat polynomial. Selanjutnya dalam penerapan bayesian boosting untuk label yang bersifat polynomial memiliki pengaruh naiknya hasil evaluasi sebesar 4.3\%. Berdasarkan hasil tersebut, saran terhadap penelitian selanjutnya dapat memilih seleksi fitur lain yang sesuai dengan karakteristik label dan data yang digunakan dalam pengolahan text mining dengan label yang bersifat polynomial.

\section{Daftar Rujukan}

[1] APJII, "Penetrasi dan perilaku pengguna internet Indonesia," 2017.

[2] P. R. C. Xu, Shuo /(Research Center for Information Science 
Theory and Methodology, Institute of Scientific and Technical Information of China, "Bayesian Nave Bayes classifiers to text classification.pdf." .

[3] N. D. Pratama, Y. A. Sari, and P. P. Adikara, "Analisis Sentimen Pada Review Konsumen Menggunakan Metode Naive Bayes Dengan Seleksi Fitur Chi Square Untuk Rekomendasi Lokasi Makanan Tradisional," J. Pengemb. Teknol. Inf. dan Ilmu Komput. Univ. Brawijaya, vol. 2, no. 9, [9] pp. 2982-2988, 2018.

[4] D. Ariadi and K. Fithriasari, "Klasifikasi Berita Indonesia Menggunakan Metode Naive Bayesian Classification dan [10] Support Vector Machine dengan Confix Stripping Stemmer," J. SAINS DAN SENI ITS Vol. 4, No.2, vol. 4, no. 2, pp. 248$253,2015$.

[5] S. Fanissa, M. A. Fauzi, and S. Adinugroho, "Analisis Sentimen Pariwisata di Kota Malang Menggunakan Metode Naive Bayes dan Seleksi Fitur Query Expansion Ranking," $J$. Pengemb. Teknol. Inf. dan Ilmu Komput., vol. 2, no. 8, pp. 2766-2770, 2018.

[6] S. Moro et al., "Leveraging national tourist offices through data analytics Leveraging national tourist of fi ces through data analytics," 2018.

[7] Y. Pramudita, U. T. Madura, S. S. Putro, and U. T. Madura, "Klasifikasi Berita Olahraga Menggunakan Metode Naïve Bayes dengan Enhanced Confix Stripping Stemmer," $J$.
Teknol. Inf. dan Ilmu Komput., vol. Vol. 5, No, no. August 2018, p. hlm. 269-276, 2019.

8] B. Aryoyudanta, T. B. Adji, and I. Hidayah, "Semi-supervised learning approach for Indonesian Named Entity Recognition (NER) using co-training algorithm," Proceeding - 2016 Int. Semin. Intell. Technol. Its Appl. ISITIA 2016 Recent Trends Intell. Comput. Technol. Sustain. Energy, pp. 7-12, 2017.

S. Chormunge and S. Jena, "Efficient feature subset selection algorithm for high dimensional data," Int. J. Electr. Comput. Eng., vol. 6, no. 4, pp. 1880-1888, 2016.

[10] L. Dini Utami and R. S. Wahono, "Integrasi Metode Information Gain Untuk Seleksi Fitur dan Adaboost Untuk Mengurangi Bias Pada Analisis Sentimen Review Restoran Menggunakan Algoritma Naïve Bayes," J. Intell. Syst., vol. 1, no. 2, pp. 120-126, 2015.

[11] X. Feng, S. Li, C. Yuan, P. Zeng, and Y. Sun, "Prediction of Slope Stability using Naive Bayes Classifier," KSCE J. Civ. Eng. 22(3)941-950, pISSN 1226-7988, eISSN 1976-3808, vol. 22, pp. 941-950, 2018.

[12] A. S. Budiman, P. Studi, T. Komputer, X. A. Parandani, P. Studi, and M. Informatika, "Uji Akurasi Klasifikasi Dan Validasi Data Pada Penggunaan Metode Membership Function Dan Algoritma C4 . 5 Dalam," vol. 9, no. 1, pp. 565-578, 2018. 